\title{
Las dos almas de la cultura de Weimar
}

Tomás Maldonado

Traducción de Nicolás López

\section{Nota preliminar}

"Le due anime della cultura di Weimar" es es título original del texto de Tomás Maldonado (1922-2018), cuya traducción al castellano ofrecemos en este número de Nuevo itinerario. Revista de filosofía. Fue publicado por primera vez en 1978, en la compilación Weimar. Lotte sociali e sistema democratico nella Germania degli anni Venti, que estuvo al cuidado de Lucio Villari (Bologna: II Mulino, pp. 153-161). El traductor quiere agradecer a los herederos de Tomas Maldonado y a la editorial Feltrinelli por haber cedido gentilmente los derechos del ensayo para la publicación de esta traducción. Para quien guarde interés por la cultura weimariana, encontrará en este texto una lúcida aproximación a las tendencias dominantes de una época que parece ya lejana, pero que en muchos aspectos sigue siendo el espejo en el que se refleja nuestra problemática modernidad.

Nicolás López

UNC-CONICET

nlopez@mi.unc.edu.ar 


\section{Las dos almas de la cultura de Weimar}

\section{Tomás Maldonado}

Asistimos hoy a un renovado interés por la República de Weimar ${ }^{1}$. Un fenómeno de moda, obviamente. Pero un fenómeno que no se presenta en ninguna parte con las mismas características. En nuestro país ${ }^{2}$, por ejemplo, la moda de Weimar no debe entenderse exclusivamente como un retorno nostálgico a las costumbres, el arte y la literatura de los «goldene Zwanziger Jahre» ${ }^{3}$. Hay algo de eso, es verdad, pero también hay más. Existe además un componente que, para ser claros, llamaremos político. Ya es bastante evidente que en nuestra curiosidad por Weimar aflora, silenciosamente, la preocupación de muchos por el destino de nuestro ordenamiento democrático. De hecho, muchos se alarman por la presunta analogía entre ciertos procesos de la Italia de hoy y aquellos de la República de Weimar; muchos temen (mientras otros esperan) que tales procesos puedan abrir el camino, en nuestro país, tal como sucedió en Weimar, a una regresión autoritaria.

Aunque admitamos la presencia de tales analogías, no creemos que puedan avalar por sí mismas la tesis de un paralelismo de fondo entre estos dos períodos históricos, y menos aún que nuestra democracia deba necesariamente seguir la misma

\footnotetext{
${ }^{1}$ Las obras a las que se hace referencia en el curso de este ensayo son las siguientes: $P$. Behrens, «Kunst und Technik», Elektrotechnische Zeitschrift, XXII, (1910); G. Benn, Provoziertes Leben, Berlin, 1955; E. Bloch, Erbschaft dieser Zeit, Frankfurt am Main, 1962; E. Bloch, Geist der Utopie, Frankfurt am Main, 1964; F. Dessauer, Technische Kultur, Kempten, 1907; A. Döblin, Berlin Alexanderplatz. Die Geschichte vom Franz Biberkopf (1929), Berlin, 1963; A. Gramsci, "Americanismo e fordismo» (1934), en Quaderni dal Carcere, Torino, 1975; H. von Hofmannsthal, "Das Schrifttum als geistiger Raum der Nation" (1927), en Erzählungen und Aufsätze, Frankfurt am Main, 1957; E. Kapp, Grundlinien einer Philosophie der Technik. Zur Entstehungsgeschichte der Kultur aus neuen Gesichtspunkten, Braunschweig, 1877; L. Klages, Der Geist als Widersacher der Seele, Bonn, 1972; R. Kühnl, G. Hardach (eds.), Die Zerstörung der Weimarer Republik, Köln, 1977; G. Lukács, “'Grosse und Verfall’ des Expressionismus», en Essays über Realismus, Neuwied, 1971; G. Martens, Vitalismus und Expressionismus, Stuttgart, 1971; L. Mittner, La letteratura tedesca del Novecento, Torino, 1960; H. Muthesius, Die Weltwirtschaft. Ein Jahr- und Lesebuch, Leipzig-Berlin, 1906; J. M. Palmier, L'expressionisme comme révolte, Paris, 1978; J. Popper, Technischen Fortschritte nach ihrer ästhetischen und kulturellen Bedeutung, Leipzig, 1888; W. Rathenau, Tagebuch 1907-1922, Düsseldorf, 1967; W. Rothe (ed.), Expressionismus als Literatur, Bern, 1969; W. Sombart, "Technik und Kultur», Archiv für Sozialwissenschaft und Sozialpolitik, XXXIII (septiembre, 1911), n. 2; M. Weber, L'etica protestante e lo spirito del capitalismo, Firenze, 1965; J. Wiesner, "NaturGeist-Technik», en Ausgewählte Reden, Vorträge und Essays, Leipzig, 1910.

${ }^{2}$ Es decir, Italia (N. del T.)

${ }^{3}$ En alemán en el original: "Dorados años veinte" (N. del T.)
} 


\section{Tomás Maldonado Traducción de Nicolás López}

suerte que la de Weimar. Pero la cuestión, además de política, es exquisitamente histórica. Por lo tanto, será mejor dejar a los historiadores la tarea de demostrar (como muchos ya lo han hecho) la absoluta falta de fundamento de tal paralelismo. Nosotros nos reservamos en este lugar una tarea más limitada: la de examinar algunos aspectos de la cultura alemana de los años veinte, intentando contrastar, en la medida de lo posible, la imagen de ella que la actual moda de Weimar ha contribuido a crear: una imagen que poco (o nada) tuvo que ver con la realidad. En síntesis: una imagen folclórica de Weimar, una "Weimar in technicolor», como la ha definido Cesare Cases.

Detengámonos un momento para examinarla más de cerca. La Weimar que aquí es oleográficamente presentada se identifica, en último análisis, con la ciudademblema del período entero: Berlín. O mejor, con un particular mito de Berlín. ¿Pero cuál? Parece que podemos ubicarlo en el Berlín convertido en mito por obra de la novela Berlin Alexanderplatz (1929) de Alfred Döblin. Basta recordar, a este propósito, que Döblin, sirviéndose de una técnica narrativa que recuerda al Manhattan Transfer (1925) de John Dos Passos, ha contribuido a crear una imagen en cierto modo fascinante, pero también considerablemente ambigua, de esta ciudad. Un Berlín que sólo en apariencia se asemeja al tradicional Berlín contestatario, tantas veces representado por Grosz, Heartfield, Dix, y ciertamente por Brecht, con su vociferante jungla humana de mendigos, borrachos, inválidos, harapientos, prostitutas, dementes, ladrones, vagabundos, rufianes. En apariencia, decimos, porque los miserables de Döblin, a diferencia de aquellos del Berlín contestatario, se revelan más bien conciliadores, y raramente expresan aversión contra los símbolos del poder constituido. Para ser claros, todos aquellos símbolos que en el cuadro de Grosz Deutschland, ein Wintermärchen (1917-1919) retratan la fuerza de la opresión y del sufrimiento. El ex-convicto Franz Biberkopf, el protagonista de Berlin Alexanderplatz, exhorta al populacho subproletario a la resignación: «¡Esta buena gente! Pero no sean tan salvajes. Quédense un poco tranquilos. Tengan un poco de paciencia a este mundo».

Es así que se pasa, de un modo casi indoloro, del estrépito de una estética de la insubordinación a la quietud de una estética de la subordinación; de un cabaret a otro. 
Es así, de hecho, que se abre el camino al uso pintoresco de aquella subcultura «Lumpen» que más tarde terminará, mediante la sutil mediación del «Goodbye to Berlin» de Christopher Isherwood, en el relumbrante cabaret hollywoodense de Bob Fosse. De la Lola de Marlene Dietrich a la Sally de Liza Minelli.

Aquí se cierra el círculo: parodiando inescrupulosamente a Berlín, la atormentada Weimar tardo-expresionista sucumbe para convertirse en una Weimar frívola, en suma, una Weimar del «musical» -ahora presentable en la sala abarcatodo de la actual sociedad capitalista.

Pero, de este modo, se ilumina con una luz de neón, de manera farsesca y mistificadora, sólo una de las dos almas de la cultura de Weimar, y se deja en sombras a la otra. Porque, vale recordarlo, las almas de Weimar son dos. Un alma retoma con nombres diversos la «cultura de la expresión». Sus raíces deben buscarse en el protoromanticismo del «Sturm und Drang» ${ }^{4}$, en la filosofía romántica de Jacobi, de Fichte y de Schelling, en la "Lebensphilosophie ${ }^{5}$ que encuentra su profeta en Nietzsche, su sistemático-antisistemático en Dilthey, su sociólogo «trágico» en Simmel. Y, obviamente, en el expresionismo de los años precedentes a la Primera Guerra mundial. Resumiendo: un alma portadora del «fanatismo de la expresión», para decirlo con Gottfried Benn. La otra alma, en cambio, profesa una «cultura de la racionalización», destinada, de modo más o menos mediato, a ser intérprete de la nueva exigencia, precisamente de racionalización, del desarrollo del aparato productivo de aquel período. Mientras la primera se vincula, sobre todo, a la tradición artístico-literaria, la segunda intenta absorber la tradición del espíritu que busca, investiga, inventa, planifica y proyecta.

Esta polaridad de la cultura de Weimar tampoco debe engañarnos; no se trata de una cesura infranqueable: son dos realidades contrapuestas, pero recíprocamente dependientes. Toda tentativa de hacer autónoma una de la otra lleva fatalmente a una visión distorsionada (y mistificante) tanto de una como de la otra. La problemática de

\footnotetext{
${ }^{4}$ El «Sturm und Drang» ("Tempestad e Ímpetu”) fue el famoso círculo artístico de la segunda mitad del siglo XVIII ligado a las figuras de Herder, el joven Goethe y Friedrich Schiller, entre otros. Su estética era una clara protesta contra la cultura racionalista de la Aufklärung. (N. del T.)

5 "Filosofía de la vida" (N. del T.)
} 
la cultura de Weimar resulta poco transparente si no se tiene en cuenta la relación dialéctica existente entre «cultura de la expresión» y «cultura de la racionalización».

Pero todo esto ¿no recuerda a la vieja dicotomía «Kultur/Zivilisation», desde siempre tan cara a los alemanes? Ciertamente. Sin embargo, el contexto histórico ha cambiado. No le está más garantizada, como antes, la impunidad. Tras el impulso del apremiante desarrollo político, social y económico de la república de Weimar, aparece ahora sometida, por así decir, a la «prueba de la verdad». En breve: es forzada a mesurarse, irremediablemente, en términos de una concreción cada vez mayor.

En los albores del siglo, H. S. Chamberlain y Ludwig Klages, dos grandes exponentes ante litteram de la ideología nazi, habían exacerbado la distancia entre «Zivilisation» y «Kultur», ya que, como decía Klages, la «Zivilisation» sería el reino negativo del «Espíritu» («Geist»), mientras la «Kultur» sería el reino positivo del «Alma» («Seele»).

Esta visión romántico-idealista, con todo su vastísimo espectro de implicaciones reaccionarias, se vincula directamente al debate en torno al problema de la máquina. Después de todo, la máquina, según tal perspectiva, es el punto focal de la «Zivilisation», y por lo tanto debe ser considerada una realidad enemiga, por antonomasia, de la «Kultur». En pocas palabras, la prueba de la verdad de la que hablábamos comienza a hacerse sentir más, a partir del momento en el cual se ve forzada a definir (o redefinir) el rol de la máquina, es decir, de la técnica, en el contexto de las tradicionales categorías de la cultura alemana. Proceso que, obviamente, se abre camino mucho antes del advenimiento de la República de Weimar. Recordemos, a este propósito, las contribuciones relativas a la cuestión de la relación técnica/cultura de E. Kapp (1977), E. Popper (1888), G. Simmel (1901), M. Weber (1905), F. Dessauer (1907), J. Wiesner (1910) y W. Sombart (1911) 6 . A partir de la década de 1910, y sobre todo después del advenimiento de la República de Weimar, la cuestión técnica/cultura se vuelve cada vez más la «cuestión de la racionalización».

\footnotetext{
${ }^{6}$ Acerca de esta cuestión y de los autores implicados en el debate, el lector puede remitirse a una nutrida colección de textos, compilada e introducida por el propio T. Maldonado, en Técnica y cultura. El debate alemán entre Bismarck y Weimar. Buenos Aires: Infinito, 2002. (N. del. T.)
} 
En este punto, es necesaria una aclaración terminológica. El término «racionalización» es usado a menudo, incluso hoy, con significados muy diversos. Se pueden mencionar, entre los más frecuentes, la racionalización entendida como concentración horizontal y vertical de un cierto número de empresas industriales con intereses comunes o convergentes; la racionalización como incremento de la productividad del trabajo y como secuencialidad lineal del proceso productivo, o sea, como «cadena de montaje»; la racionalización comprendida como intervención sobre la forma de los productos, para hacerlos más adecuados a las necesidades específicas de la producción de masas. Las últimas dos modalidades constituyen los elementos cardinales de aquella filosofía de la producción conocida como "fordismo» o «taylorismo-fordismo».

Walther Rathenau, presidente de la AEG (Allgemeine Elektrizitäts-Gesellschaft ${ }^{7}$ ) y ministro de la República de Weimar, es un ejemplo de cómo los hombres más iluminados del capitalismo alemán -y Rathenau estaba entre los primeros-intentaban hacer avanzar el tema de la racionalización, sin invalidar la sacrosanta dicotomía «Kultur/Zivilisation». Propone el fordismo, pero con «mala conciencia». A diferencia de Henry Ford, que naturalmente no tenía remordimientos en contra del propio fordismo, Rathenau adhiere con reservas mentales de todo tipo. Con reservas sobre todo «culturales». Mientras el capitalismo americano de la época de Ford avanza seguro de sí, convencido de su rol en el proceso de la "gran transformación», el capitalismo alemán del período guillermino y weimariano aparece a menudo incierto, atormentado, temeroso de violentar los valores culturales de su pasado precapitalista. Rathenau se mueve en esta línea: quiere el fordismo, pero se niega a asumir la responsabilidad, al menos públicamente, de las vulgares estridencias de la «fanfarria del fordismo", como lo decía Gramsci.

Sus reflexiones sobre la «mecanización del mundo» parecen teñidas de una tenue melancolía crepuscular. Frente al mito del hombre rapsódicamente solo del expresionismo, Rathenau hace notar la dificultad práctica de vivir ese papel en el

\footnotetext{
7 En español, "Sociedad General de Electricidad". Desde sus inicios, la empresa se ocupaba de la producción y distribución de electricidad, incluida la fabricación de sus propios accesorios técnicos (cables, lámparas, dinamos, motores, etc.). Pero, además, tenía a su cargo la producción de casi todos los electrodomésticos de la época. (N. del T.)
} 


\section{Tomás Maldonado Traducción de Nicolás López}

contexto de los países industrializados, aquellos países que él llama «civiles»: «En los países civiles, observa, no se puede imaginar oficio más complicado o difícil que aquel del eremita». Pero en otros momentos sugiere que, en el vasto proceso de «mecanización del mundo», un acuerdo entre «mecanizados» y «eremitas» sería deseable, al menos en parte. Lo que tiene en mente es una suerte de pacto de noagresión, sobre todo de no-interferencia en las tareas específicas de cada uno. Dejando a un lado las metáforas: una verdadera y propia «división del trabajo», ya que esto significaría, en la práctica, garantizar a los «mecanizados» la dirección autónoma de la «cultura de la racionalización», y a los «eremitas», la de la «cultura de la expresión». Tal diseño debería llevar a la primera a una mayor eficacia operativa, y a la segunda, a una mayor libertad creativa.

¿Pero qué se ocultaba realmente en esta confrontación entre eficacia y libertad? Sin querer ser demasiado reductivos, se puede afirmar que la estrategia de la «racionalización industrial» -entendida sobre todo como fordismo- no es de ningún modo extraña a esta confrontación. Al contrario: es su raíz. Bastaría con mostrar los términos en que se desarrolló el debate sobre la relación arte/industria, arte/técnica en los primeros quince años de este siglo. Los artistas, en particular los representantes del supuesto "arte aplicado», querían intervenir sobre la forma de los productos fabricados en serie, por medio de una simple transferencia de la modalidad formal (o estilístico-formal) elaborada en la práctica artística pura. Pero la práctica artística de aquellos años, fuertemente condicionada por el "fanatismo de la expresión», presentaba propuestas en abierto conflicto con aquella modalidad formal del producto que la industria consideraba más adecuada a la nueva exigencia de la racionalización productiva.

El mejor intérprete de esta perspectiva de la gran industria es quizás Hermann Muthesius. En 1906 escribía: «La máquina está perfectamente capacitada para emprender la fabricación de los objetos industriales satisfactoriamente, porque no se predispone a imitar el trabajo manual. La máquina tiene sus formas propias. Son las formas que derivan, obviamente, de la modalidad misma del proceso de fabricación. Serán formas esencialmente lisas, de superficies pulidas, porque en eso consiste la 
fuerza de la máquina. Estas encarnan el modo de fabricación, así como las pequeñas imprecisiones y la individualidad constituyen el encanto del objeto producido a mano. De cuanto hemos dicho, se deriva que para los objetos fabricados por la máquina se debe crear un nuevo universo formal».

Mucho más próxima a la posición de Rathenau, al menos hasta cierto punto, es aquella asumida al inicio de la década de 1910 por Peter Behrens, arquitecto y diseñador industrial de la AEG. Como sucedía con Rathenau, también en Behrens se puede percibir, en ocasiones, una mala consciencia, aunque no es igual el modo en que se manifiesta. En el primero, la ambigüedad -lo hemos visto- parece disolverse, aparentemente, en la astuta (y salomónica) propuesta de una «división del trabajo». No sucede así en Behrens. La transparente ambigüedad de su posición parece no despertarle vergüenza alguna: con extrema desenvoltura, de hecho, lo vemos oscilar entre el lema «la forma sigue la electricidad» y la adhesión entusiasta a la filosofía de la anti-civilidad (esto es, de la anti-técnica) de H. S. Chamberlain.

Pero el más grande esfuerzo analítico sobre la naturaleza del conflicto entre «cultura de la expresión» y «cultura de la racionalización» fue llevado a cabo por Ernst Bloch, en el escrito Geist der Utopie («El espíritu de la utopía») (1918-1923). Bloch, siguiendo en cierto sentido el rastro de Simmel, su maestro, avanza la hipótesis de que la co-presencia de estos dos mundos -el mundo de la "gran expresión» («Grosse Expression») y el mundo de la "gran técnica» («grosse Technik»)- es «trágica», es decir, fatal y necesaria. Sin embargo, rechaza $-\mathrm{y}$ en esto reside su originalidadcualquier forma de tregua entre las dos fuerzas implicadas. Rechaza, por lo tanto, la posición del tipo Rathenau, y obviamente también la del tipo Muthesius. Pero rechaza, sobre todo, las actitudes de duplicidad consoladora, de sermoneante mediación entre la «Zivilisation» de la AEG y la «Kultur» de Chamberlain y Klages, reconocibles en los escritos de Behrens en torno a 1910. El interés de Bloch es el de eternizar el antagonismo. No sólo eso: busca exacerbar la virulencia. Porque esta exacerbación sería la única capaz de mantener vivo en la historia, precisamente, el «Geist der Utopie». 


\section{Tomás Maldonado Traducción de Nicolás López}

Sin embargo, ni siquiera Bloch se muestra consecuente hasta el final, dejando entrever lo que verdaderamente le importa: imponer a los objetos de uso producidos por la industria, la servidumbre estilística -acaso un híbrido entre «Biedermeier» y «Jugendstil»- de la expresión. Con la complicidad de un «arte aplicado de nivel superior» («Kunstgewerbe höherer Ordnung»), que se situaría, como él dice, entre la silla (objeto de uso) y la estatua (objeto de expresión). Para Bloch, la «cultura de la expresión» sería capaz, por medio de tal estrategia, de permear toda la «cultura de la racionalización». El expresionismo dejaría así de ser una forma artístico-literaria, de un radio de influencia algo reducido, para devenir una estrategia global del «espíritu de la utopía». Una estrategia no transitoria, sino interminable, porque igualmente interminable es el expresionismo -siempre según Bloch. De esta forma, su «Geist der Utopie» termina por identificarse con el «Plan der Vorsehung» («plan de la Providencia») de Hegel.

Esta visión no debe sorprendernos: Bloch fue de hecho uno de los más tenaces defensores de la estética ( $y$ también de la ética) expresionista. Baste recordar a este propósito su contribución al famoso «expressionismus-Debatte» de los años treinta, que involucró, además de Bloch, a personalidades como Lukács, Klaus Mann, Kurella, Brecht. En esa ocasión, Bloch constataba: «la herencia del expresionismo no está todavía terminada. Porque aún no ha comenzado». (Y es preciso admitir que el resurgir de ciertas orientaciones de la actual neo-vanguardia y de cierta forma de comportamiento en las actuales subculturas juveniles, de indudable matriz expresionista, hacen pensar que la predicción de Bloch no fue tan desacertada).

La aproximación blochiana privilegia pues, una vez más, la «cultura de la expresión». Deberíamos decir por qué, desde entonces, no se han hecho grandes progresos en la profundización de la cuestión relativa a la otra alma de Weimar, como la habíamos llamado: a saber, la «cultura de la racionalización». En realidad, se continúa sabiendo muy poco (o nada) sobre la relación de recíproca influencia existente entre esta cultura y la verdadera y propia racionalización del aparato productivo. Ni se sabe qué rol ha jugado en el progresivo debilitamiento de la democracia de Weimar -además, obviamente, de los bien conocidos factores 
Las dos almas de la cultura de Weimar

estructurales- el no haber sabido identificar un espacio de acción cultural por fuera del combate entre expresión y racionalización. Y este punto no se debe subestimar: como en la época de la república de Weimar, también en la nuestra es un espacio que falta. 